\title{
Analysis of the precipitation mechanisms of partially coherent precipitates in the 15-5 $\mathrm{PH}$ alloy
}

\author{
H.R. HABIBIBAJGUIRANI, C. SERVANT ${ }^{*}$ and G. CIZERON
}

Laboratoire de Structure des Matériaux Métalliques, Bât. 465, ISMA, Université de Paris-Sud, 91405 Orsay cedex, France

* Laboratoire de Métallurgie Structurale, UA 1107 du CNRS, Bât. 413, ISMA, Université de Paris-Sud, 91405 Orsay cedex, France

Abstract : The formation and growth of some of the different precipitates observed in the first stage of the structural hardening occurring in the $15-5 \mathrm{PH}$ alloy in the temperature range 400$650^{\circ} \mathrm{C}$ are discussed in terms of different approaches.

\section{INTRODUCTION}

The 15-5 PH (Precipitation Harrening is a martensitic stainless alloy used in the nuclear and aeronautic fields. The grade studied in the present paper had the following chemical composition (in weight \%): Balance $\mathrm{Fe}-14.8 \mathrm{Cr}-4.87 \mathrm{Ni}-3.10 \mathrm{Cu}-0.21 \mathrm{Mo}-0.30 \mathrm{Nb}-0.28 \mathrm{Si}$ and $0.041 \mathrm{C}$. By hardness measurements and classical transmission electron microscopy observations, we have shown that the precipitation occurs in two successive main stages as a function of temperature and/or time [1]. On the TTP (Temperature, Time, Precipitation) diagram, are reported the different precipitates observed the

formation and growth mechanisms of some of them are discussed below; they are referred to as $\mathrm{A} \rightarrow \mathrm{E}$, see Figure 1.
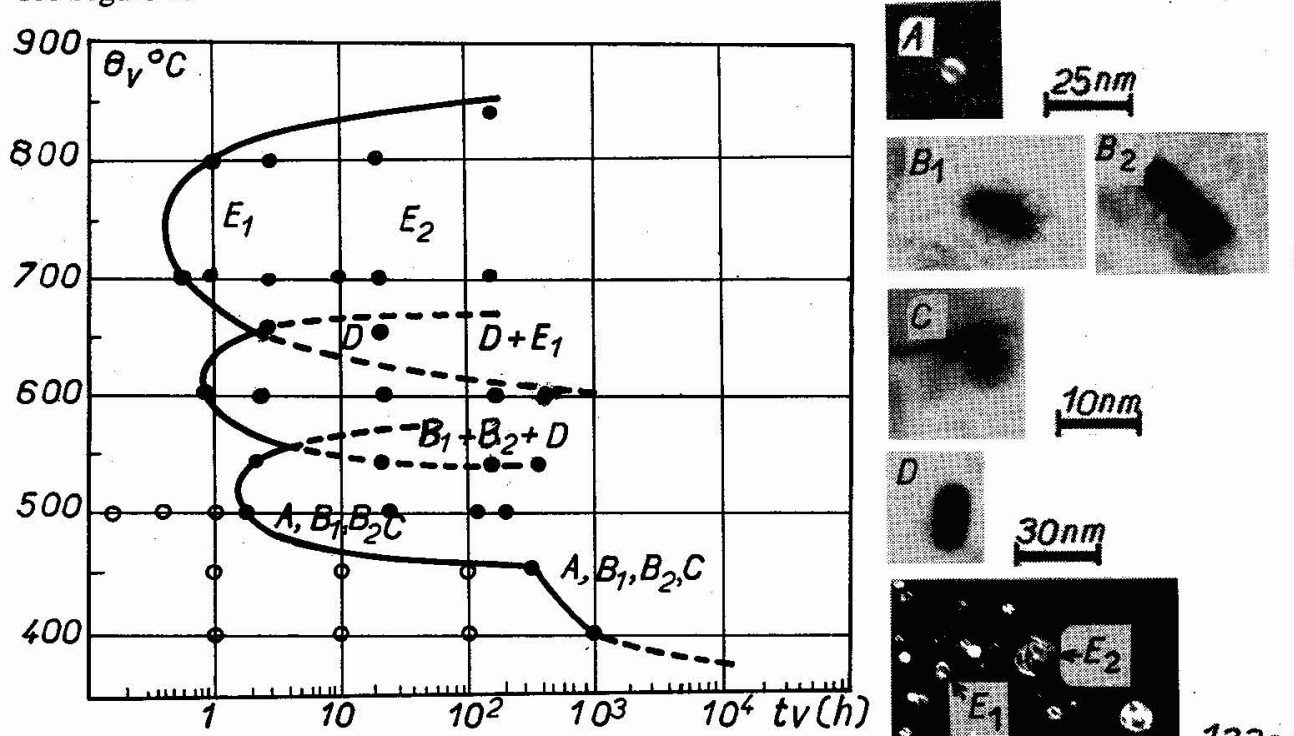

$14 n m$
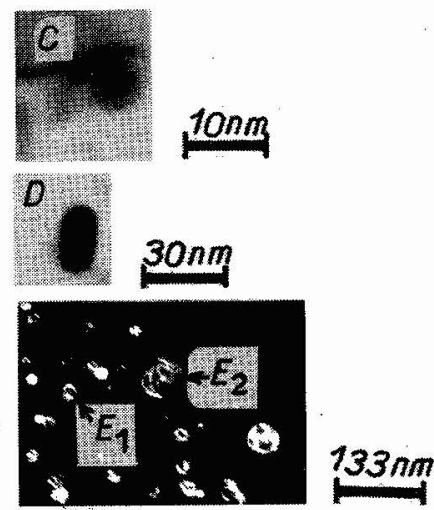

Figure 1 : TTP diagram of the $15-5 \mathrm{PH}$ alloy 


\section{RESULTS AND DISCUSSION}

First, at the very beginning of ageing, the stage of coherent precipitation was not clearly revealed by classical TEM. Some precipitates noted as A seem to present a no-contrast line and a spherical strain field of the b.c.c. matrix. They give rise to faint diffraction spots very close to those of the b.c.c. matrix. By using the KHACHATURYAN model describing the crystal lattice rearrangement as a stressfree transformation strain $[2,3]$, some informations can be obtained concerning the coherent decomposition of the cubic solid solution in two phases also cubic: b.c.c. solute $(\mathrm{Cu})$ enriched precipitates with the concentration embedded within a b.c.c. solute $(\mathrm{Cu})$ depleted matrix with the $\mathrm{c}_{\mathrm{o}}$ concentration. The formation of the coherent precipitates is accompanied by an elastic strain of the matrix due to the difference in size of the $\mathrm{Cu}$ and $\mathrm{Fe}$ atoms. For a binary alloy, the mismatch parameter $\varepsilon_{0}$ can be written in terms of the concentration coefficient of crystal lattice expansion as follows:

$$
\varepsilon_{0}=\frac{d a}{d c}\left(c-c_{o}\right)
$$

where $\mathrm{da} / \mathrm{dc}$ is the concentration coefficient of linear expansion if the Vegard law holds. We used the crystalline parameter data published for the Fe-Cu model alloys [4 - 5] and also took into account the value of the parameter of the b.c.c. matrix of the 15-5 PH alloy. In addition, $\mathrm{c}$ and $\mathrm{c}_{\mathrm{o}}$ were respectively taken equal to 1 and 0 due to $\mathrm{X}$-ray microanalysis results obtained on bigger precipitates formed later on [6]. The competition between the elastic and interfacial energies considered as isotropic determines the equilibrium shape of a precipitate. This latter is related to the value of the $\mathrm{K}$ parameter which is equal to $r_{0} / \sqrt[3]{V}$, where $V$ is the precipitate volume having the $R$ radius, and $r_{0}$ is expressed as follows , [3]:

$$
r_{o}=\gamma_{s} \frac{c_{11}\left(c_{11}+c_{12}+2 c_{44}\right)}{\left(2 c_{44}+c_{12}-c_{11}\right)\left(c_{11}+2 c_{12}\right)^{2} \varepsilon_{o}^{2}}
$$

$\gamma_{\mathrm{S}}$ is the surface tension $\left.(0.125 \mathrm{~J} / \mathrm{m} 2),[7]\right), c_{i j}$ are the elastic moduli of the material (those of pure iron were used: $\mathrm{c} 11, \mathrm{c} 12$ and $\mathrm{c} 44$ are respectively equal to $24.2,14.65$ and $11.21011 \mathrm{dyne} / \mathrm{cm} 2$.) and the precipitate radius $R$ was estimated to $2 \mathrm{~nm}$. So, $K$ was found equal to 66 (8). If $K>1$, the contribution of the interfacial energy is dominant and the precipitate is equiaxed. In the case of the Au-Fe system, for which $\mathrm{K}=28.4$, therefore $>1$, spherical precipitates were indeed observed by HREM [9]. When the precipitate grows, the $K$ value decreases and the elastic contribution increases. For $K \ll<1$, the equiaxed precipitate transforms into a platelet. In addition, if the elastic moduli met the requirement: $c_{11}-c_{12}-$ $2 \mathrm{c}_{44}<0$, condition occurring in the 15-5 PH alloy, the habit plane of the platelet is $\{001\},[2]$.

After a given time of ageing of the 15-5 PH alloy, the precipitates observed by classical TEM and referred to as B are partially coherent. The B1 type was revealed by an apparent double lobe strain field contrast and $\mathrm{B} 2$ by a striated contrast, Figure $2 \mathrm{a}$. These defects might correspond to fine twins as observed by [10] in overaged model $\mathrm{Fe}-\mathrm{Cu}$ and $\mathrm{Fe}-\mathrm{Cu}-\mathrm{Ni}$ alloys in which the globular precipitates had a twinned 9R close-packed structure which would be generated by a martensitic transformation from the metastable b.c.c. matrix. The B precipitates give rise to streakings approximately across the diffraction spots of the b.c.c. matrix on which a maximum of intensity is observed close to the positions of f.c.c. spots. Hence, when the coherent spherical b.c.c. precipitates (A) grow, they lose progressively their coherency and adopt a plate morphology and become B type. These latter grow and become semicoherent and appear as more or less regular rods (D type), Figure $2 b$. Their crystalline structure is f.c.c. and they present the Kurdjumov and Sachs orientation relationship with the b.c.c. matrix, Figure 2c. Furthermore, from $X$ ray microanalysis, the chemical composition of the $B$ and $D$ type precipitate is very enriched in copper [6].

The formation of the B type precipitates has been comparatively analysed - first on the base of the theory developed by WESCHLER[11] for the martensitic transformation and we applied to the inverse K.S. b.c.c. $\rightarrow$ f.c.c.transformation, - secondly using the formalism developed by DAHMEN and WESTMACOTT [12]. In the former case, after the homogeneous deformation of BAIN, three shear systems of the b.c.c. matrix were considered: $\{101\}<11 \overline{1}>,\{101\}<\overline{1} 11>$ and $\{11 \overline{2}\}<111>$; this third system has not been previously analysed by [12]. The invariant lines we found for the three shear possibilities were: $\langle 656\rangle$, $\langle 557\rangle$ and $\langle 110\rangle$ b.c.c. and the habit planes: $\{110\},\{112\}$ and 
\{123]b.c.c.. In the latter case, [12] proposed that the transformation from the b.c.c. structure (having the crystalline parameter of iron) to the f.c.c. structure (having the $\mathrm{Cu}$ parameter) involves almost no change in atomic volume: The large strains of the BAIN deformation can be converted almost entirely into simple shears by appropriate rotations between matrix and precipitate lattices. In Figure $3 a$ is shown the production of the $\langle\overline{5} 57\rangle$ invariant line. The angle $\Theta_{\mathrm{Li}}$ is expressed between the invariant line and the [001] zone axis according to the relation established by [13] and equal to:

$\left.\tan \Theta_{\mathrm{Li}}=\left\{\left|\mathrm{a}^{2}-1\right| / \mid 1-\mathrm{c} 2\right\}\right\}^{1 / 2}$ where a and $\mathrm{c}$ are the principal deformations of the b.c.c. lattice.

The respective rotation of the lattices is characterized by an angle $\Phi \simeq 7^{\circ}$ which is very close to as well the shear angle $\left(6.7^{\circ}\right)$ of the WESCHLER theory as the value $\left(5.16^{\circ}\right)$ corresponding to the angle of the K. S. orientation relationship. In Figure $3 \mathrm{~b}$ is illustrated the production of the $\langle 656\rangle$ invariant line by a rotation of $3.25^{\circ}$. On the base of the DAHMEN formalism, we were unable to give account of the $<110>$ invariant line which has been calculated only once with the third shear possiblity (compared to five times for $\langle 656\rangle$ and $<\overline{557\rangle}\rangle$ ), so this invariant line is obviously less frequent.
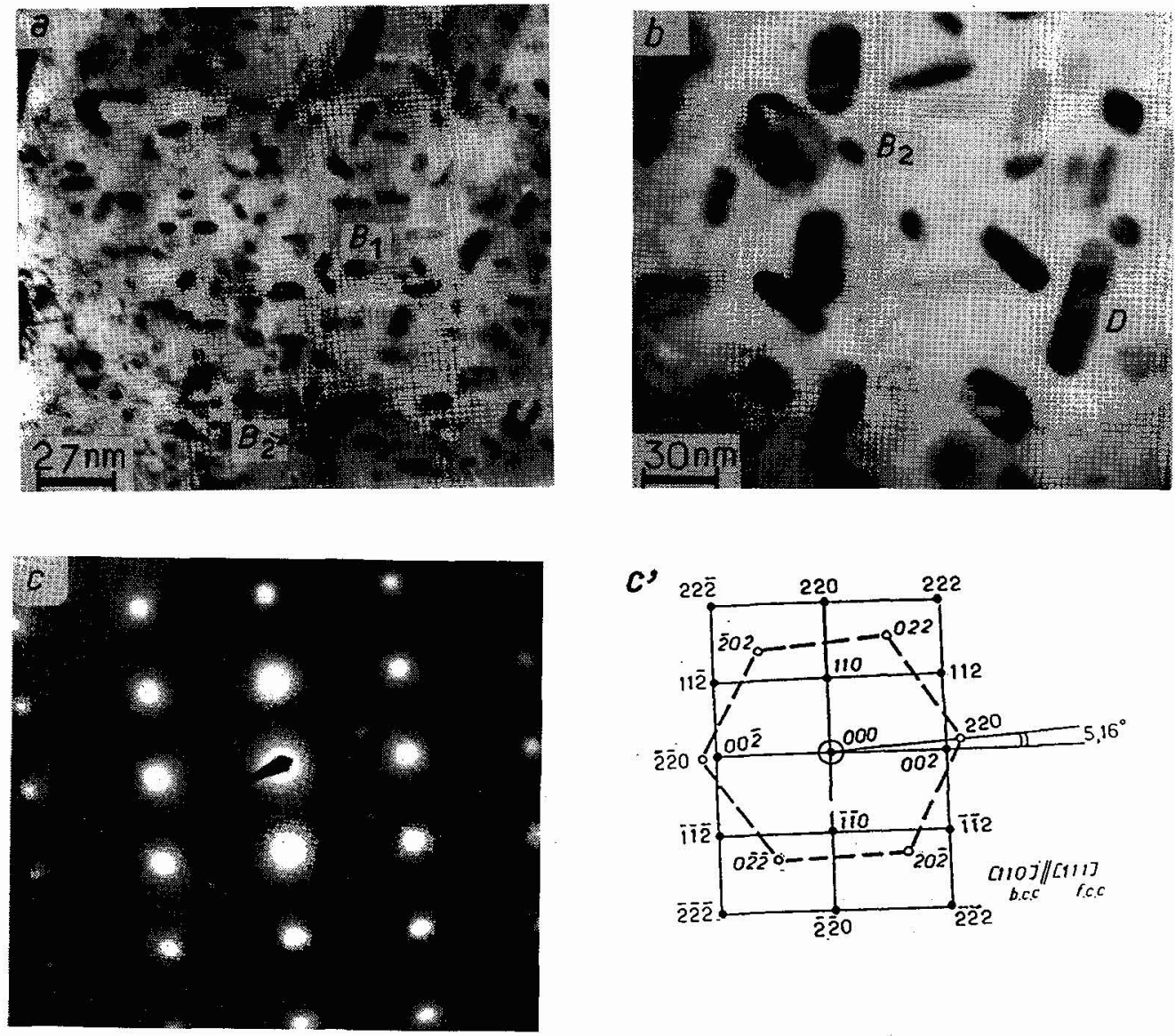

Figure 2: Bright fields showing the $\mathrm{B} 1$ and $\mathrm{B} 2$ type precipitates (a: $256 \mathrm{~h} / 500^{\circ} \mathrm{C}$ ageing), the $\mathrm{D}$ type (b: $64 \mathrm{~h} / 650^{\circ} \mathrm{C}$ ageing). Electron diffraction pattern illustrating the K.S. orientation relationship (c: $64 \mathrm{~h} / 600^{\circ} \mathrm{C}$ ageing) and the schematic representation (c'). 
The growth direction of the B precipitates which will become D type for longer ageing has been associated with the invariant line along which the misfit is the lowest. Indeed, on TEM bright fields, where the B2 and D type precipitates coexist, the D precipitates have grown along the $<557>$ b.c.c., i.e. $\simeq<111>$ directions whereas the B2 precipitates (smaller than the D type precipitates) have not grown probably because their main direction is $\langle 851\rangle \simeq\langle 110\rangle$ b.c.c., a less frequent and probably less favourable growth direction.
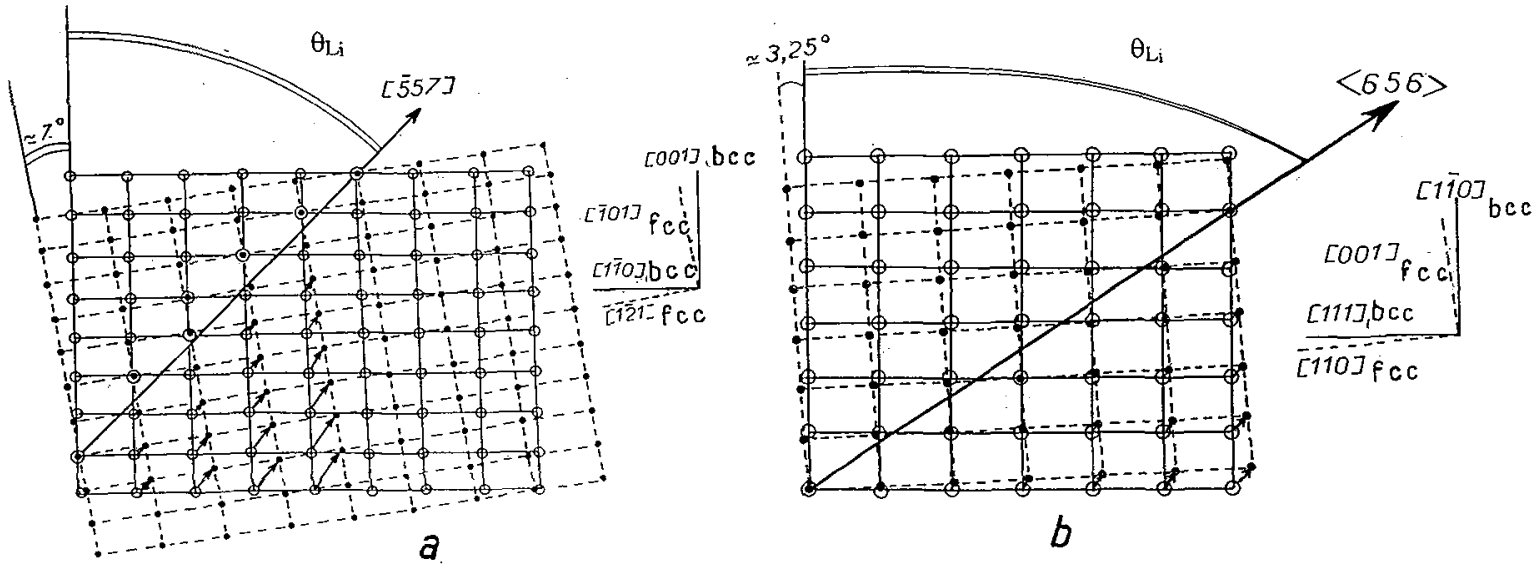

Figure 3 : Production of the invariant lines of the $<\overline{557}>$ (a) and $<656>$ (b) type by respective rotation of the b.c.c. and f.c.c. lattices according to the formalism of DAHMEN.

\section{CONCLUSION}

The precipitation in the 15-5 PH industrial alloy is very complex especially in the early beginning of ageing (A type precipitates) and needs further investigations in particular by HREM to compare the present results with those found in model binary $\mathrm{Fe}-\mathrm{Cu}$ or $\mathrm{Fe}-\mathrm{Cu}-\mathrm{Ni}$ alloys. As for $\mathrm{B}$ and $\mathrm{D}$ type precipitates, both formalisms of WESCHER and DAHMEN have led to the determination of the invariant line, giving a predominant growth direction close to $<111>$ b.c.c.

\section{REFERENCES}

[1] - H.R. HABIBI BAJGUIRANI, C. SERVANT and G. CIZERON, Acta Metall. Mater., vol. 41, n'5, (1993), pp. 1613-1623.

[2] - A.G. KHACHATURYAN, Thery of structural transformations in solids, John Wiley and Sons, New-York, (1983).

[3]-A.G. KHACHATURYAN and D.E. LAUGHLIN, Acta Metall. Mater., vol. 38, n 10, (1990), pp. $1823-1835$.

[4] - W.B. PEARSON, a handbook of lattice spacings and structures of metals and alloys, Pergamon Press, New-York, (1958).

[5] - E. HORNBOGEN, Acta Met., vol. 10, (1962), p. 525.

[6] H.R. HABIBI BAJGUIRANI, R. MOLINS, C. SERVANT, J.L. STRUDEL and G. CIZERON, (1993), to be published.

[7]- G.R. SPEICH and R.A. ORIANI, TMS-AIME, vol. 233, (1965), p. 623.

[8] - H.R. HABIBI BAJGUIRANI, Thèse de Doctorat en Science, Université de Paris-Sud, (Mars 1993).

[9] - Chen-Chia-Chou and C.M. WAYMAN, J. Mater. Res., vol. 7, n² 2, (1992), pp. 321-328.

[10] - P.J. OTHEN, M.L. JENKINS, G.D.W. SMITH and W.J. PHYTHIAN, Phil. Mag. Letters, vol. $64, n^{\circ} 6,(1991)$, pp. 383-391.

[11]-M.S. WESCHLER, Acta Met., vol. 7, (1959), p. 793.

[12]-U. DAHMEN, Scripta Metall., vol. 15, (1981), p. 77.

U. DAHMEN, FERGUSON and K.H. WESTMACOTT, Acta Met., vol. 35, (1987), p. 1037.

U. DAHMEN, K.H. WESTMACOTT, vol. 35, (1986), p. 475.

[13]-J.M. HOWE and D.A. SMITH, Acta Met., vol. 40, (1992), p. 2343. 